\title{
A RARE CASE OF HYDATID DISEASE IN THIGH
}

Manju Singh ${ }^{1}$, Amit Agrawal2 ${ }^{2}$ Sandeep Chandrakar ${ }^{3}$, Gambhir Singh ${ }^{4}$

\section{HOW TO CITE THIS ARTICLE:}

Manju Singh, Amit Agrawal, Sandeep Chandrakar, Gambhir Singh. "A Rare Case of Hydatid Disease in Thigh". Journal of Evolution of Medical and Dental Sciences 2015; Vol. 4, Issue 18, March 02; Page: 3197-3200,

DOI: $10.14260 /$ jemds $/ 2015 / 464$

ABSTRACT: We report a rare case of hydatid cyst in thigh in a 35 years old male patient who presented with swelling of size $8 \times 9 \mathrm{~cm}$ in right upper thigh since 12 years and pain in swelling since 1 month. Based on clinical features provisional diagnosis of Rhabdoomyosacroma / lipoma thigh / Neurofibroma was made - results of fine needle aspiration cytology were inconclusive. USG of lump showed an intramuscular well defined fusiform lesion $(10 \times 5 \times 6.3 \mathrm{~cm})$ in postero-medial aspect of right thigh with multiple, variable sized cysts. Excision of lump was done which revealed well encapsulated, intramuscular soft and cystic swelling. On cut section, multiple typical shiny daughter cysts were seen. Histopathological examination confirmed it to be hydatid cyst of thigh.

KEYWORD: Hydatid cyst thigh, extrahepatic hydatid cyst, E. granulosus.

INTRODUCTION: The occurrence of the hydatid cysts in the thigh is rare. Most of the hydatid cysts are reported in the liver and lungs. It has also been reported in fallopian tube, uterus, mesentery, pancreas and diaphragm. We are reporting this uncommon and rare case in a middle aged patient.

Surgical resection was done with an excellent prognosis. The purpose of this case report is to draw attention towards the extra hepatic and extra- abdominal manifestations of E. grannulosus in addition to its rarity.

CASE REPORT: A 35 years old male patient was admitted because of palpable mass in right upper thigh in posteromedial aspect since 12 years and pain in the swelling since 1 month. Pain was vague dull acting in nature, low to medium in intensity and localized only over swelling, non-radiating in nature, aggravated on movement of lower limb and relieved on taking rest.

On examination, he was average built male, afebrile, no lymphadenopathy, no abdominal symptoms. Local examination revealed non-tender, solitary swelling, present over posteromedial aspect of right upper thigh, soft to firm in consistency, measuring about $8 \times 9 \mathrm{~cm}$, ovoid in shape with smooth surface and well defined margins. Color of skin over swelling was normal. There was no impulse on coughing and no pulsation felt over selling. Swelling was freely mobile in relaxed position and mobility was restricted when muscles of medial compartment of thigh were contracted. Fluctuation and, transillumination were negative but was dull on percussion. On auscultation, no thrill or bruit was heard.

Routine lab investigations were within normal limits, esoinophil count within normal limits. Fine needle aspiration cytology reports inconclusive, USG of right thigh was performed which was suggestive of a fusiform lesion situated in posteromedial aspect of right thigh with multiple variable sized cysts within it. Lesion was well defined capsulated and intramuscular.

Features were suggestive of hydatid cyst in right thigh. The surgery was planned and complete excision of well encapsulated intramuscular cystic lump was done with preservation of all important vessels, nerves and muscles.

On gross examination, there were multiple daughter cysts within the mother cysts; hydatid fluid and sand were also present. 
Post-operative period was uneventful and patient was discharged after removal of all stitches. Mebendazole was prescribed and the patient was advised for regular follow up. Histopathological report was also conclusive of hydatid cyst.

DISCUSSION: More than $90 \%$ of hydatid cysts occur in the liver, lungs, or both. Peripheral organ hydatidosis is very uncommon, as few embryos can escape the capillary filtering systems of the liver and lung. ${ }^{1}$

Primary hydatid disease of the skeletal muscle is rare and present only in $3 \%$ of patients. Theoretically the muscle is hospitable for echinococcal interactions because of its contractility and high level of lactic acid. ${ }^{2}$

Most of the previous reports of primary muscular hydatidosis have been isolated intramuscular localizations.,2,3 Bayram and Siricki reported the $1^{\text {st }}$ inter muscular hydatid cysts in forearm region of 18 year old man.

Preoperative diagnosis and evidence of diagnostic biopsy or aspiration is crucial in preventing local recurrence, cystic infection, and anaphylactic shock. ${ }^{1}$

Rim and multicystic appearance are typical features of hydatid cysts. However, various patterns such as unilocular cysts, multilocular lesion and atypical complex or solid lesion may be observed. ${ }^{4}$

Detection of circulating antibodies against several antigens, immune diagnosis of cystic echinococcus has been used in both primary diagnosis and patients follow up after treatment. ELISA, indirect immune florescence antibody test, immune electrophoresis and immune blast tests are other modalities. $.6,6,7,8,9$

Compared to imaging method, serological assay are less expensive and easier to perform. Serology has high sensitivity for liver, $80-100 \%$, and a lesser sensitivity of lung cysts 55\% and even lesser sensitivity in other organ involvement, $25-56 \% .^{5}$

In our case, no preoperative diagnosis could be made appropriately but the USG led to a presumptive diagnosis of hydatid cyst in our patient. ${ }^{10}$

Hydatid cyst should be considered in the differential diagnosis of soft tissue swelling, especially in endemic areas.

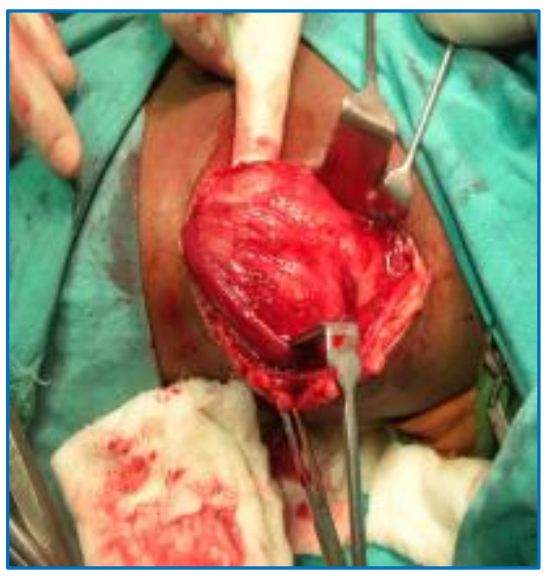

Fig. 1: Cyst dissected out from thigh

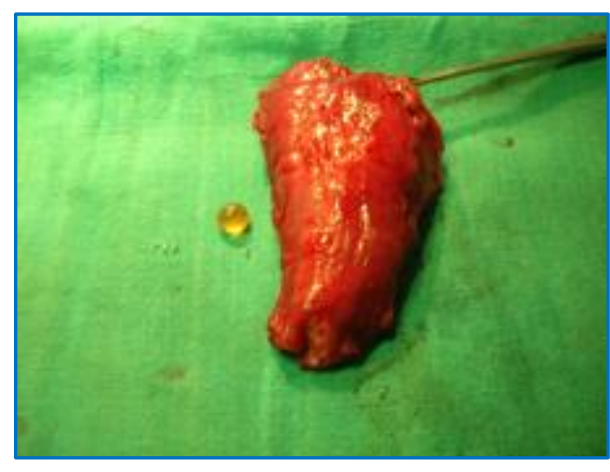

Fig. 2: Cyst

J of Evolution of Med and Dent Sci/ eISSN- 2278-4802, pISSN- 2278-4748/ Vol. 4/ Issue 18/ March 02, 2015 Page 3198 


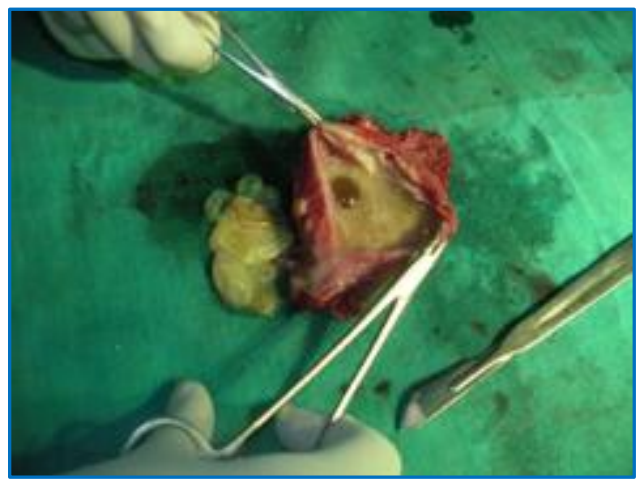

Fig. 3: Cyst Cut Open

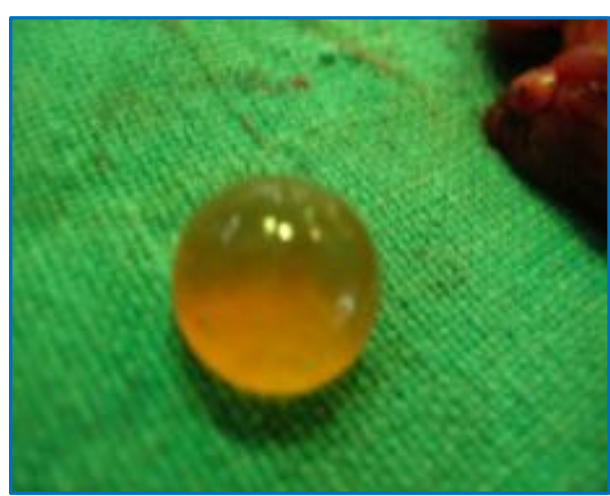

Fig. 4: Cyst Cut Open

\section{REFERENCES:}

1. Sayek I, Onat D: Diagnosis and treatment of uncomplicated hydatid cyst of the liver. World J Surg 25:21-27, 2001.

2. Unusual presentation of an infected primary hyadatid cyst of biceps femoris muscle - Skeletal radiology/springer Berlin/ Heidelberg 0364-2348 (print) 1432-2161 (online) vol 31 number 10 / October 2002 case report - faculty of medicine , Gaziantep University , Radyoloji ABD, Kolejtep, Gazzi Turkey.

3. Primary inter muscular Hyadatid cyst - A case Report- S G Joshi, S D Deodhar, M H Kamat , J Post Grad Med 1963; 28 ,135-137 : ICID : 325450.

4. Biava MF, Dao A, Fortier B: Laboratory diagnosis of cystic hydatic disease. World J Surg 25:10$14,2001$.

5. Zaouche A, Haouet $\mathrm{K}$, Jouini M, et al: Management of liver hydatid cysts with a large biliocystic fistula: Multicenter retrospective study. Tunisian Surgical Association. World J. Surg 25:28-39, 2001.

6. Ertem M, Uras C, Karahasanoglu T, et al: Laparoscopic approach to hepatic hydatid disease. Dig Surg 15:333-336, 1998.

7. Akhan 0, Ozmen MN: Percutaneous treatment of liver hydatid cysts. Eur J Radiol 32:76-85, 1999.

8. Khuroo MS, Wani NA, Javid G, et al: Percutaneous drainage compared with surgery for hepatic hydatid cysts. N Engl J Med 337:881-887, 1997.

9. Saimot AG: Medical treatment of liver hydatidosis. World J Surg.

10. Gharbi HA, Hassine W, Brauner MW, et al: Ultrasound examination of the hydatic liver Radiology 139:459-463, 1981. 


\section{AUTHORS:}

1. Manju Singh

2. Amit Agrawal

3. Sandeep Chandrakar

4. Gambhir Singh

\section{PARTICULARS OF CONTRIBUTORS:}

1. Associate Professor, Department of General Surgery, Pt. JNM Medical College, Raipur.

2. Assistant Professor, Department of General Surgery, Pt. JNM Medical College, Raipur.

FINANCIAL OR OTHER

COMPETING INTERESTS: None
3. Assistant Professor, Department of General Surgery, Pt. JNM Medical College, Raipur.

4. M D, Samarpan Hospital, Raipur.

\section{NAME ADDRESS EMAIL ID OF THE} CORRESPONDING AUTHOR:

Dr. Amit Agrawal,

HIG C/72, Shailendra Nagar,

Raipur, C. G-492001.

E-mail: doc.amitagarwal@gmail.com

Date of Submission: 05/02/2015.

Date of Peer Review: 06/02/2015.

Date of Acceptance: 20/02/2015.

Date of Publishing: 02/03/2015. 